\title{
TWO-STAGE INTRACRANIAL AND ORBITAL OPERATION FOR GLIOMA OF THE OPTIC NERVE*
}

\author{
BY \\ N. S. JAIN \\ Department of Ophthalmology, Irwin Hospital, New Delhi, India
}

From the ophthalmological standpoint the indications for a combined intracranial and orbital operation are few. The extirpation of an orbital neoplasm is a relatively simple task in an average case, the choice lying between the anterior or lateral approach.

Davis (1940) preferred the anterior route even for the removal of gliomata of the optic nerve, a view supported by Bailey (1940) but opposed, dogmatically, by Dandy (1941). Because of the post-operative complications of ptosis, strabismus, and ocular immobility, some neurosurgeons prefer a transfrontal craniotomy for all kinds of orbital tumours on the grounds of a better cosmetic result, an easier approach, and a more thorough and complete excision under direct vision (Dandy, 1922, 1941; Rand, Irvine, and Reeves, 1939; Woods, 1940; Jefferson, 1940; Benedict, 1949; Ingraham and Matson, 1954). A lateral orbitotomy may not, however, always lead to complications (Jain, 1957), and Hanberry (1956) says that the after-effects of a careful dissection and gentle traction of the orbital contents are only transient.

Jean (1922), Ray and McLean (1943), and Shannon, Jaeger and Forster (1944) advocated a combined operation in cases of retinoblastoma, but this method was not supported by Reese (1931) and Jain (1950).

Jefferson (1940), Wilson and Farmer (1940), Bucy, Russell, and Whitsell (1950), McFarland and Eisenbeiss (1950), Love, Dodge, and Bair (1955), Gramberg-Danielsen (1955), Hanberry (1956), Fowler and Matson (1957), and Dodge, Love, Craig, Dockerty, Kearns, Holman, and Hayles (1958) favour a combined operation in cases of glioma of the optic nerve to prevent involvement of the chiasma. Marshall (1954), however, said that an attempt to remove a glioma of the optic nerve in the short distance between the foramen and chiasma endangered the latter and did not ensure a thoroughly complete excision. Knapp (1941) reported three cases with enlarged optic foramina treated by Kronlein's orbitotomy, which had no intracranial invasion after 15 to 17 years. A survival period of over 20 years was reported by Craig and Dodge (1955) after biopsy of the intracranial portion

* Received for publication February 16, 1960. 
of the optic nerve, and by Hudson (1940) after an incomplete extirpation. This is because of the remarkably slow rate of growth of most gliomata of the optic nerve (Grade I or II: Kernohan, 1948). Donahue (1955) reported an orbital recurrence 20 years after an orbital operation, which was apparently incomplete.

However, despite differences of opinion, an enlarged optic foramen carries the threat of an intracranial invasion by the gliomatous process. In such cases a combined or two-stage intracranial and orbital operation is indicated, as exemplified in the case described below.

\section{Case Report}

A girl aged 12 years developed progressive visual loss and proptosis of the right eye in January, 1958. In October, 1958, the visual acuity in the right eye was only light perception. The right eyeball was proptosed and pushed down and out, and the right upper eyelid was ptosed and the ocular movements markedly restricted, particularly in adduction and depression. The right optic disc was pale and swollen. A skiagram of the skull showed no abnormality, except enlargement of the optic foramen. All laboratory investigations were negative, except that the erythrocyte sedimentation rate was raised to $44 \mathrm{~mm}$./ $\mathrm{hr}$ (Westergren). A diagnosis of right-sided optic nerve glioma with intracranial extension was made. (This case has also been referred to by Mathai and Chandy, 1959.)

First Operation.-A right fronto-temporal craniotomy was performed on October 8, 1958. The intracranial part of the right optic nerve was excised just distal to the optic chiasma. No orbital exploration was carried out.

Bits of friable whitish tissue were found to be composed of loosely-knit fibres and spindle-shaped nuclei with many blood vessels. Some areas were so fibrous as to suggest neurofibroma, but this pattern was only occasionally seen. The diagnosis of astrocytoma was made.

Follow-up.-Immediately after the operation a course of deep $x$-ray therapy was given but the proptosis remained unaltered. On May 1, 1959, the proptosis was $18 \mathrm{~mm}$. on the right side (Fig. 1A), the eyeball was displaced down and out, ptosis was present (Fig. 1B), and all ocular movements were absent.

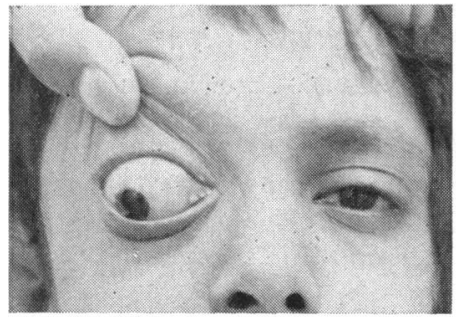

FIG. 1A.-Proptosis $18 \mathrm{~mm}$., right eye diverged.

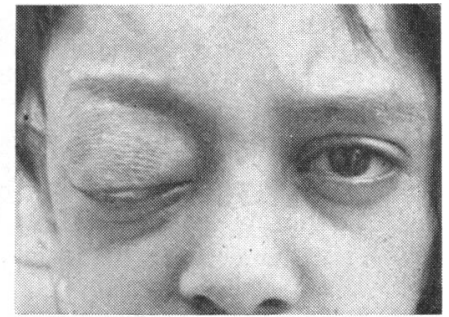

FIG. 1B.-Appearance of ptosis before orbitotomy.

There was no perception of light and the pupil was dilated and fixed. The fundus showed a kidney-shaped swollen disc, tortuous and engorged veins, superficial flameshaped haemorrhages near the macula, and multiple exudates all over the retina. The skin of the right temple was pigmented and cicatrized by irradiation. 
A skiagram showed the marks of the craniotomy and an enlarged right optic foramen (Fig. 2).

FiG. 2.-Skiagram showing marks of craniotomy and enlarged optic foramen (arrows).

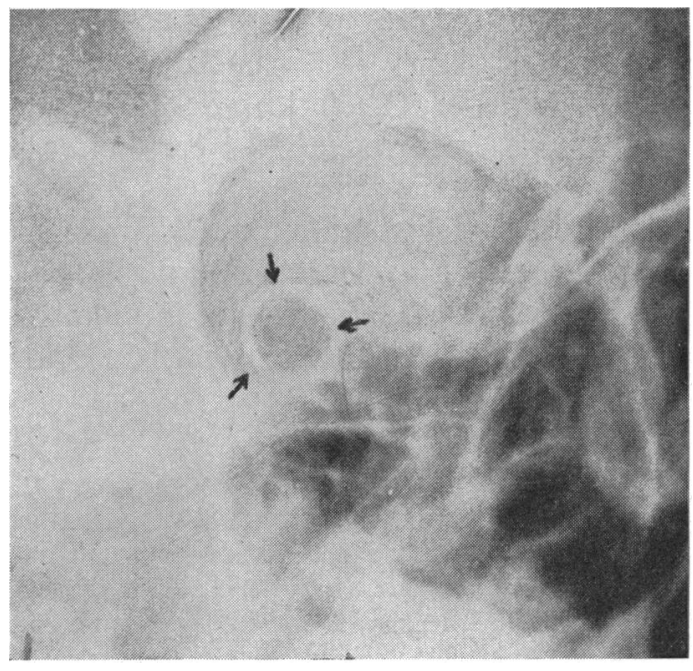

Second Operation.-A lateral orbitotomy was performed on May 19, 1959, and a glioma of the right optic nerve was excised.

One week later the skin sutures were found to have cut through and the wound had gaped, exposing the bony fragment. A rotation " $C$ "-shaped skin-graft was provided to cover the bone, but on June 12, 1959, the skin had again contracted leaving the bone on the right temple (Fig. 3), and the dead sequestrum had to be removed before the operative wound healed. The proptosis was reduced by $15 \mathrm{~mm}$., but the right eye remained divergent (Fig. 3), ptosis persisted, and all ocular movements were absent.

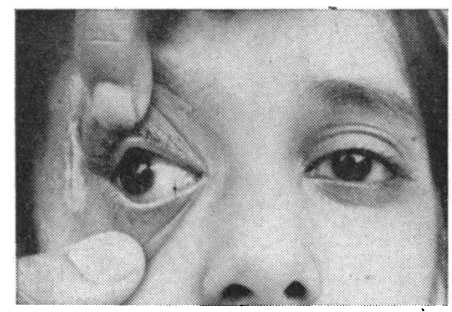

FIG. 3.-Proptosis reduced to 3 mm., but right eye still divergent.

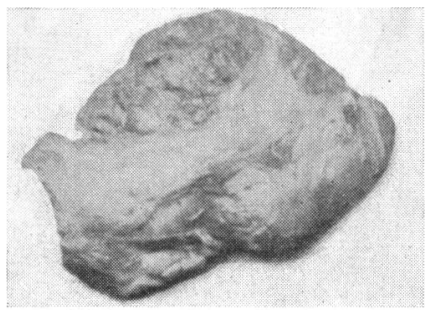

FIG. 4.-Excised neoplasm.

Pathological Report.-Macroscopically the nerve sheaths were intact. The neoplasm measured $14 \mathrm{~mm}$. in length and $9 \mathrm{~mm}$. in diameter (Fig. 4). The diagnosis of glioma of the optic nerve was confirmed by microscopic examination (Fig. 5, opposite).

Fundus Examination.-2 weeks after the operation the disc was distorted and pale, the physiological cup being obliterated as if filled with a fluffy exudate. The margins of the disc were hazy, merging into a greyish, pale, and oedematous retina. The arteries emerging from the disc were completely empty and could be traced to the periphery as whitish streaks. The whitish-looking veins near the disc turned pinkish when traced to the periphery. The fundus reflex was pale in the central and juxtapapillary zone, but towards the periphery retained an orange hue. A few superficial haemorrhages were 


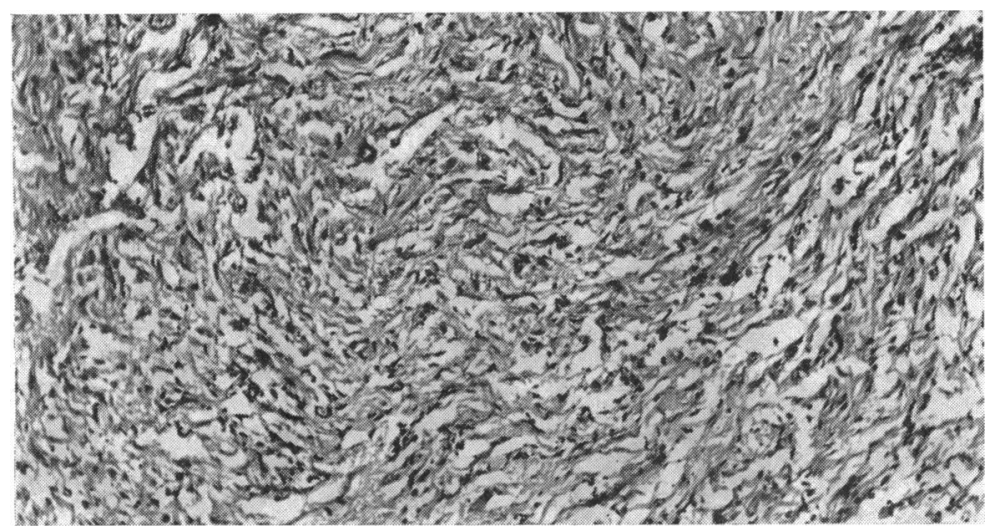

Fig. 5.-Section of neoplasm. $\times 75$.

present here and there, but at several places, often adjacent to the blood vessels, large fluffy cotton-wool type exudates were seen, some of which suggested haemorrhages in the process of absorption or organization.

Follow-up.-The patient returned on February 27, 1960, with rapidly progressive blindness of the left eye. The visual acuity was reduced to counting fingers at $18 \mathrm{in}$., and two weeks later to counting fingers at 3 in. The pupil was dilated and reacted slightly and sluggishly to light, with marked optic atrophy. Numerous new loops of dilated veins were present on the temporal surface of the white optic disc and near its temporal edge, and a skiagram showed an enlarged optic foramen. The appearance of the right eye was the same as at the time of discharge.

\section{Discussion}

The term "two-stage intracranial and orbital operation" is clearer than the term "combined operation", which might imply that both the cranial and the orbital fields were explored at the same time.

In view of the clinical evidence of an intracranial extension, the only alternative to the two-stage procedure adopted in this case would have been a "combined" one-stage cranial cum orbital operation for a radical excision. For obvious reasons the anterior approach was impossible, and the lateral approach alone could not have been expected to facilitate extirpation in toto.

The turning of the bony fragment into a sequestrum, necessitating its removal, may have been due to a surgical mistake, but it was postradiational atrophy and cicatrization of the skin which caused the bone to become uncovered. The presence of ptosis, strabismus, and ocular immobility did not result from the orbitotomy, since they were present from the first.

Radiotherapy was useless in this case, an observation supported by Fowler and Matson (1957) and Wagener (1959), but Martin and Cushing (1923), Cushing (1930), Grinker (1930), Jefferson (1940), and Dyke and Davidoff (1952) recommended irradiation in cases of chiasmal involvement.

The few reports of the appearance of the fundus after section of the optic nerve near the globe (Verhoeff, 1922; Davis, 1940; Marshall, 1954; Wagener, 1959) show considerable variation. 
Despite a thorough eradication of the neoplasm by what seemed to be the most complete, correct, and certain method, the rapid onset of total blindness, caused presumably by a transchiasmal extension of the gliomatous process into the contralateral optic nerve, leaves the prognosis uncertain.

\section{Summary}

A case of glioma of the right optic nerve with evidence of an intracranial extension is described. A two-stage cranial and orbital operation did not relieve the blindness, and the left eye also became blind a few months later.

I wish to thank Dr. K. V. Mathai and Dr. J. Chandy of the Department of Neurology and Neurosurgery, Christian Medical College, Vellore, India, who, having performed the cranial operation, supplied their own clinico-surgical data, and permitted me to report this case. I am grateful to the staff of the Department of Ophthalmology, Irwin Hospital, New Delhi, and to Drs. R. C. Agarwal, H. Mohan, and A. C. Chadha in particular, for assistance in the orbital operation and the post-operative care of the patient.

My thanks are also due to Prof. J. P. Agarwal, Professor of Ophthalmology, All-India Institute of Medical Sciences, New Delhi, for arranging to supply the photomicrograph.

\section{REFERENCES}

BAIley, P. (1940). Arch. Ophthal. (Chicago), 23, 1018.

BENEDICT, W. L. (1949). Amer. J. Ophthal., 32, 763.

Bucy, P. C., Russell, J. R., and WhITSEll, F. M. (1950). Arch. Ophthal. (Chicago), 44, 411.

Craig, W. McK., and DodGe, H. W., Jr. (1855). Proc. Mayo Clin., 30, 21.

Cushing, H. (1930). Arch. Ophthal. (Chicago), 3, 704.

DANDY, W. E. (1922). Amer. J. Ophthal., 5, 169. (1941). Arch. Ophthal. (Chicago), 25, 191.

DAvis, F. A. (1940). Ibid., 23, 735.

Dodge, H. W., Jr., Love, J. G., Craig, W. McK., Dockerty, M. B., Kearns, T. P., Holman, C. B., and HAYLES, A. B. (1958). A.M.A. Arch. Neurol., 79, 607.

DonAHUE, H. C. (1955). A.M.A. Arch. Ophthal., 54, 259.

DYKE, C. G., and DAVIDOFF, L. M. (1942). "Roentgen Treatment of Diseases of the Nervous System", pp. 100-103. Lea and Febiger, Philadelphia.

FowleR, F. D., and MATSON, D. D. (1957). J. Neurosurg., 14, 515.

Gramberg-DanifLSEN, B. (1955). Confin. neurol. (Basel), 15, 240.

GRINKER, R. R. (1930). Arch. Ophthal. (Chicago), 4, 497.

HANBERY, J. W. (1956). Stanford med. Bull., 14, 34.

Hudson, A. C. (1940). Proc. roy. Soc. Med., 33, 685.

INGRAHAM, F. D., and Matson, D. D. (1954). "Neurosurgery of Infancy and Childhood", p. 331. Thomas, Springfield, Ill.

JAIN, N. S. (1950). Brit.J. Ophthal., 34, 709. (1957). Ibid., 41, 767.

Jean, G. W. (1922)., Arch. Ophthal. (N.Y.), 51, 505.

JEFFERSON, G. (1940). Proc. roy. Soc. Med., 33, 688.

KERNOHAN, J. W. (1948). Rocky Mtn med. J., 45, 962.

KNAPP, A. (1941). Arch. Ophthal. (Chicago), 25, 213.

LoVE, J. G., DoDGE, H. W., Jr., and BLAIR, H. L. (1955). A.M.A. Arch. Ophthal., 54, 386.

MCFARLAND, P. E., and EISENBEISS, J. (1950). Amer. J. Ophthal., 33, 463.

MARShaLl, D. (1954). Ibid., 37, 15.

MARTIN, P., and Cushing, H. (1923). Arch. Ophthal. (N.Y.), 52, 209.

MATHAI, K. V., and ChANDY, J. (1959). Neurology (Bombay), 7, 3.

RAND, C. W., IRVINE, R., and REEVES, D. L. (1939). Arch. Ophthal. (Chicago), 21, 799.

RAY, B. S., and MCLEAN, J. M. (1943). Ibid., 30, 437.

REESE, A. B. (1931). Ibid., 5, 269.

SHANNON, C. E. G., JAEGER, R., and Forster, F. M. (1944). Trans. Amer. ophthal. Soc., 42, 326.

VERHOEFF, F. H. (1922). Arch. Ophthal. (N.Y.), 51, 120, 239.

WAGENER, H. P. (1959). Amer. J. med. Sci., 237, 238.

WILSON, J. M., and FARMER, W. D. (1940). Arch. Ophthal. (Chicago), 23, 605.

Woods, A. C. (1940). Ibid., 23, 1021. 